\title{
Peran Auditor Internal dalam Pendeteksian dan Pencegahan Fraud Pada Bank Syariah di Kota Bandung
}

\author{
Yogi Ginanjar'), E. Mulya Syamsul' ${ }^{2)}$ \\ ${ }^{1.2}$ Fakultas Ekonomika dan Bisnis, Universitas Majalengka \\ *Email korespondensi: yogi.ginanjar@ unma.ac.id
}

\begin{abstract}
Bareskrim Polri has named two BJB Syariah Bank officials in Bandung City as suspects in a fictitious credit case worth Rp 548 billion. This is one of the big cases that has tarnished Islamic banking, especially in the city of Bandung. The purpose of this research is to conduct a deeper study of the role of internal auditors in detection and prevention of fraud at Islamic Banks in Bandung City. The research method used is descriptive analysis and verification with the type of survey. The independent variable used is the role of the internal auditor. Meanwhile, fraud detection and prevention is used as the dependent variable. The population of this research is all Islamic Banks in Bandung City. The sampling technique used random sampling in order to obtain a sample of 60 Islamic Bank employees in the city of Bandung. The data analysis used was correlation coefficient analysis, determination and hypothesis testing. The role of the Internal Auditor affects Fraud Detection by 26.72\%. Meanwhile, the role of the Internal Auditor has an effect on Fraud Prevention by $43.16 \%$.
\end{abstract}

Keywords : the role of the internal auditor; fraud detection; fraud prevention; Islamic Bank; Bandung

Saran sitasi: Sobah, A. N., \& Rifai, F. Y. A. (2020). Peran Auditor Internal dalam Pendeteksian dan Pencegahan Fraud Pada Bank Syariah di Kota Bandung. Jurnal Ilmiah Ekonomi Islam, 6(03), 529-534. doi:http://dx.doi.org/10.29040/jiei.v6i3.1392

DOI: http://dx.doi.org/10.29040/jiei.v6i3.1392

\section{PENDAHULUAN}

Perbankan yang ada Indonesia mengalami perkembangan dan perubahan yang pesat. Hal tersebut ditandai tumbuhnya bank syariah, bank-bank swasta baru dan banyak ragam produk bank yang ada di masyarakat. Bank ialah badan usaha di bidang keuangan yang berfungsi menarik dan mengeluarkan uang di masyarakat (Kamus Besar Bahasa Indonesia, 2015). Bank syariah merupakan suatu bank yang menggunakan prinsip hukum islam dalam menjalankan usahanya dan diatur oleh Fatwa Majelis Ulama Indonesia. Prinsip-prinsip tersebut diantaranya prinsip keseimbangan dan keadilan, universalisme, kemaslahatan dan tidak mengandung riba, zalim, gharar, maysir dan obyek haram (Otoritas Jasa Keuangan, 2020).

Menurut (Nasim \& Mediawati, 2019) Bank syariah merupakan lembaga perantara keuangan antara pihak yang membutuhkan dana dan pihak yang mempunyai dana, dan merupakan entitas syariah yang mempunyai fungsi untuk memperlancar lalu lintas pembayaran. Falsafah mendasari kegiatan usaha bank yaitu terkait kepercayaan dari masyarakat. Hal ini tampak pada kegiatan utama bank yaitu menerima simpanan masyarakat dalam bentuk tabungan, deposito berjangka, giro dan pemberian kredit untuk pihak yang memerlukan dana.

Kemajuan perbankan yang makin pesat menimbulkan persaingan ketat antara bank. Persaingan tersebut mengakibatkan dunia perbankan makin dinamis dan menuntut bank untuk berusaha lebih efektif dan efisien dengan tujuan untuk mempertahankan dan meningkatkan eksistensinya di masyarakat. Usaha perbankan yang efektif dan efisien akan mendorong bank menghasilkan laba maksimum. Umat Islam dan masyarakat tentunya sangat berharap akan perkembangan dari Bank Syariah yang ada di Indonesia (Santosa, Tho'in, \& Sumadi, 2020).

Bank harus bisa meminimalisir sistem yang tidak tepat agar memiliki keunggulan bersaing. Bank sangat rentan sebagai media untuk melakukan sebuah kecurangan. Kecurangan ialah manipulasi dan 


\section{Jurnal Ilmiah Ekonomi Islam, 6(03), 2020, 530}

penipuan yang sengaja dilakukan sehingga menimbulkan kerugian bagi pihak lain. Umumnya kecurangan dalam bidang keuangan berkaitan korupsi yaitu dengan mengungkapkan fakta-fakta menyesatkan, penyalahgunaan atau pelanggaran aturan. Kinerja keuangan bank tergambar dengan kondisi keuangan bank pada suatu periode tertentu dan dilihat pula dari tingkat rendahnya tingkat kecurangan bank itu sendiri. Auditor adalah salah satu peran yang dibutuhkan untuk mendeteksi dan mencegah kecurangan tersebut (M. Febri dan Yogi, 2020).

Auditor Internal diharapkan selalu menjaga integritas secara berkesinambungan dengan meningkatkan kompetensi serta selalu siap berada di depan dan menjadi mitra yang profesional (Badan Pengawas Keuangan dan Pembangunan, 2020). Sehingga peran auditor menjadi penting untuk meminimalisir kemungkinan yang akan terjadi.

Fraud atau kecurangan dalam lingkungan bisnis mempunyai arti khusus yaitu suatu kebohongan disengaja, ketidakbenaran melaporkan aset perusahaan, atau manipulasi data keuangan sehingga menguntungkan pihak tertentu. Fraud yang biasa dilakukan yaitu manipulasi pencatatan, menghilangkan dokumen atau mark-up yang merugikan keuangan masyarakat atau perusahaan. Fraud tidak cukup ditangani dengan dilakukannya pencegahan, namun fraud juga harus dideteksi sedini mungkin (Widaningsih \& Hakim, 2015).

OJK mencatat 108 kasus tindak pidana perbankan hampir dua tahun selama tahun waktu 2014-2016. Pada tahun 2018 juga OJK mengungkap kasus tindak pidana dalam dunia perbankan yang ada di Bekasi. Direktorat Tindak Pidana Korupsi Bareskrim Polri telah menetapkan dua pejabat Bank BJB Syariah di Kota Bandung sebagai tersangka dalam kasus kredit fiktif senilai Rp 548 miliar. Ini merupakan kasus yang sangat besar sehingga mencoreng perbankan syariah khususnya di Kota Bandung (Arief, 2019).

Sehingga OJK bekerja keras untuk terus mengawasi dan menganalisis dengan ketat kegiatan yang dilakukan oleh perbankan di Indonesia. Hasil temuan OJK dalam kegiatan fraud yang sering dilakukan oleh perbankan yaitu dengan modus operasi pencatatan palsu dan dengan sengaja tidak melakukan pencatatan transaksi kegiatan usaha (Otoritas Jasa Keuangan, 2020).
Faktor penyebab adanya kecurangan tidak terlepas dari konsep fraud triangle yaitu tekanan (pressure) berupa dorongan seseorang melakukan kecurangan yang diakibatkan kebutuhan finansial, yang kedua ialah kesempatan (opportunity) yang terjadi karena kurang ketatnya pengendalian internal, dan terakhir yaitu rasionalisasi (rationalization) berupa sikap pembenaran oleh pelaku dengan merasionalkan tindakan kecurangan tersebut (Tuanakotta, 2012).

Peran auditor internal memiliki peranan penting dalam mengevaluasi aktivitas sistem pengendalian, dan memberi masukan untuk peningkatannya seringkali memiliki peranan signifikan dalam mengawasi kegiatan operasi perusahaan. Pada umumnya auditor hanya dapat memeriksa apakah laporan keuangan perusahaan sudah sesuai dengan PSAK, dimana laporan keuangan tersebut merupakan hasil dari kegiatan operasional tersebut.

Menurut (Badan Pengawas Keuangan dan Pembangunan, 2015) peran ideal bagi auditor internal yaitu peran auditor internal dalam pendeteksian fraud dan peran auditor internal dalam pencegahan fraud. Menurut (Tugiman, 2013) indikator dari peran auditor internal yaitu auditor internal harus mandiri dan terpisah dari berbagai kegiatan yang diperiksa, auditor internal harus dapat bekerja secara teliti dalam melaksanakan pemeriksaan dan auditor harus menyesuaikan dengan kebijakan, rencana, prosedur dan ketentuan perundang-perundangan.

Termotivasi oleh pemaparan yang telah diungkapkan diatas, tujuan penelitian ini yaitu ingin melakukan kajian lebih dalam tentang peran auditor internal dalam pendeteksian dan pencegahan fraud pada Bank Syariah di Kota Bandung. Sehingga diharapkan dengan penelitian ini dapat merumuskan pemecahan masalah terkait dengan pentingnya peran auditor internal di dalam suatu organisasi.

Hipotesis yang dikembangkan dalam penelitian ini yaitu dimana hipotesis pertama menyatakan bahwa peran auditor internal berpengaruh terhadap pendeteksian fraud dan hipotesis kedua menyatakan bahwa peran auditor internal berpengaruh terhadap pencegahan fraud. Penelitian ini diharapkan dapat menjawab hipotesis yang dinyatakan oleh peneliti dan dapat merumuskan pemecahan masalah yang terjadi.

\section{METODE PENELITIAN}

Penelitian ini sebagai dasar atau basic research dengan jenis survey. Metode deskriptif dan verifikatif 
adalah metode yang akan dipakai untuk meneliti pendeteksian dan pencegahan fraud pada penelitian ini. Variabel independen yang digunakan ialah peran auditor internal. Sedangkan pendeteksian dan pencegahan fraud digunakan sebagai variabel dependennya. Populasi penelitian ini adalah seluruh Bank Syariah di Kota Bandung. Teknik sampling menggunakan random sampling sehingga diperoleh sampel sebanyak 60 Karyawan Bank Syariah di Kota Bandung.

Data kualitatif digunakan sebagai pendukung penelitian ini dengan sumber data primer atau langsung. Pengumpulan data menggunakan kuesioner dan wawancara dengan responden. Pengujian instrumen penelitian menggunakan uji validitas dan reliabilitas. Analisis data yang digunakan yaitu analisis koefisien korelasi, determinasi dan uji hipotesis.

\section{HASIL DAN PEMBAHASAN}

\subsection{Hasil Penelitian}

Korelasi partial digunakan untuk menganalisis bila peneliti bermaksud mengetahui pengaruh atau hubungan antar variabel independen dan dependen, dimana salah satu variabel independennya dibuat tetap atau dikendalikan (Sugiyono, 2018).

\section{Tabel 1}

Hasil Koefisien Korelasi Secara Partial X-Y1 Correlations

\begin{tabular}{|ll|r|r|}
\hline & $\begin{array}{c}\text { Pendeteksian } \\
\text { Fraud }\end{array}$ & $\begin{array}{c}\text { Peran } \\
\text { Auditor } \\
\text { Internal }\end{array}$ \\
\hline Pearson & Pendeteksian Fraud & 1,000 &, 517 \\
Correlation & Peran Auditor Internal &, 517 & 1,000 \\
Sig. (1- & Pendeteksian Fraud &. &, 000 \\
tailed) & Peran Auditor Internal &, 000 &. \\
N & Pendeteksian Fraud & 60 & 60 \\
& Peran Auditor Internal & 60 & 60 \\
\hline
\end{tabular}

Sumber: Hasil dari SPSS 21 (Diolah sendiri, 2020)

Berdasarkan tabel 1 dapat diketahui bahwa nilai koefisien korelasi Peran Auditor Internal dengan Pendeteksian Fraud pada Bank Syariah di Kota Bandung sebesar 0,517, maka keeratan hubungan antara Peran Auditor Internal dengan Pendeteksian Fraud termasuk dalam kategori sedang yaitu berada pada interval $0,40-0,599$ dan bernilai positif. Hal ini menunjukan bahwa terdapat hubungan searah antara Peran Auditor Internal dengan Pendeteksian Fraud pada Bank Syariah di Kota Bandung, artinya jika Peran Auditor Internal pada Bank Syariah di Kota Bandung tinggi maka Pendeteksian Fraud pun tinggi dan sebaliknya apabila Peran Auditor Internal pada Bank Syariah di Kota Bandung rendah maka Pendeteksian Fraud pun rendah.

Tabel 2

Hasil Koefisien Korelasi Secara Partial X-Y2 Correlations

\begin{tabular}{|ll|r|r|}
\hline & & $\begin{array}{c}\text { Pencegahan } \\
\text { Fraud }\end{array}$ & $\begin{array}{c}\text { Peran } \\
\text { Auditor } \\
\text { Internal }\end{array}$ \\
\hline Pearson & Pencegahan Fraud & 1,000 &, 657 \\
Correlation Peran Auditor Internal &, 657 & 1,000 \\
Sig. (1- & Pencegahan Fraud &. &, 000 \\
tailed) & Peran Auditor Internal &, 000 &. \\
N & Pencegahan Fraud & 60 & 60 \\
& Peran Auditor Internal & 60 & 60 \\
\hline
\end{tabular}

Sumber: Hasil dari SPSS 21 (Diolah sendiri, 2020)

Berdasarkan tabel 2 dapat diketahui bahwa nilai koefisien korelasi Peran Auditor Internal dengan Pencegahan Fraud pada Bank Syariah di Kota Bandung sebesar 0,657, maka keeratan hubungan antara Peran Auditor Internal dengan Pencegahan Fraud termasuk dalam kategori kuat yaitu berada pada interval 0,60-0,799 dan bernilai positif. Hal ini menunjukan bahwa terdapat hubungan searah antara Peran Auditor Internal dengan Pencegahan Fraud pada Bank Syariah di Kota Bandung, artinya jika Peran Auditor Internal pada Bank Syariah di Kota Bandung tinggi maka Pencegahan Fraud pun tinggi dan sebaliknya apabila Peran Auditor Internal pada Bank Syariah di Kota Bandung rendah maka Pencegahan Fraud pun rendah.

Untuk mengukur berapa besar kontribusi variabel bebas berpengaruh terhadap variabel terikat dapat dihitung dengan suatu besaran yang disebut koefisien determinasi yang dinyatakan dengan presentase (Sugiyono, 2018). Untuk menghitung besarnya kontribusi pengaruh Peran Auditor Internal terhadap Pendeteksian Fraud pada Bank Syariah di Kota Bandung digunakan rumus KD sebagai berikut:

$$
\begin{aligned}
\mathrm{KD} & =\mathrm{r}^{2} \times 100 \% \\
& =(0,517)^{2} \times 100 \% \\
& =26,72 \%
\end{aligned}
$$

Berdasarkan perhitungan diatas, dapat diketahui bahwa nilai koefisien determinasi pengaruh Peran Auditor terhadap Pendeteksian Fraud sebesar 26,72\% artinya kontribusi Pendeteksian Fraud pada Bank Syariah di Kota Bandung dipengaruhi oleh Peran Auditor Internal sebesar 26,72\% dan korelasinya dalam kategori sedang.

Untuk menghitung besarnya kontribusi pengaruh Peran Auditor Internal terhadap Pencegahan Fraud 
pada Bank Syariah di Kota Bandung digunakan rumus KD sebagai berikut:

$\mathrm{KD}=\mathrm{r}^{2} \times 100 \%$

$$
\begin{aligned}
& =(0,657)^{2} \times 100 \% \\
& =43,16 \%
\end{aligned}
$$

Berdasarkan perhitungan diatas, dapat diketahui bahwa nilai koefisien determinasi pengaruh Peran Auditor terhadap Pencegahan Fraud sebesar 43,16\% artinya kontribusi Pencegahan Fraud pada Bank Syariah di Kota Bandung dipengaruhi oleh Peran Auditor Internal sebesar 43,16\% dan korelasinya dalam kategori kuat.

Uji partial atau lebih dikenal dengan uji t yaitu untuk mengetahui signifikansi pengaruh variabel independensi (Peran Auditor Internal) secara partial atau individual menerangkan variabel dependen (Pendeteksian dan Pencegahan Fraud), pengujian ini menggunakan SPSS dengan hasil sebagai berikut:

Tabel 3

\section{Hasil Uji Partial X-Y1}

Coefficients ${ }^{\mathrm{a}}$

\begin{tabular}{||r|r|r|r|r|r|}
\hline Model & \multicolumn{2}{|c|}{$\begin{array}{c}\text { Unstandardized } \\
\text { Coefficients }\end{array}$} & $\begin{array}{c}\text { Standardized } \\
\text { Coefficients }\end{array}$ & $\mathrm{t}$ & Sig. \\
\cline { 2 - 7 } & $\mathrm{B}$ & $\begin{array}{c}\text { Std. } \\
\text { Error }\end{array}$ & Beta & & \\
\hline & & & & \\
\hline (Constant) & 18,153 & 5,384 & & 3,372 &, 001 \\
1 Peran &, 584 &, 127 &, 517 & 4,596 &, 000 \\
$\begin{array}{l}\text { Auditor } \\
\text { Internal }\end{array}$ & & & & & \\
\hline
\end{tabular}

a. Dependent Variable: Pendeteksian Fraud

Sumber: Hasil dari SPSS 21 (Diolah sendiri, 2020)

Berdasarkan tabel 3 dapat dilihat bahwa nilai $\mathrm{t}$ hitung pada Pendeteksian Fraud adalah sebesar 4.596, $\mathrm{t}_{\text {tabel }}$ sebesar 2.001 dengan tingkat signifikansi sebesar 0,000 . Karena nilai $t$ hitung $>t$ tabel yaitu $4.596>2.001$ dan nilai signifikansi $0.000<0.5$ maka Ho ditolak dan Ha diterima. Hal ini berarti Pendeteksian Fraud berpengaruh signifikan terhadap Peran Auditor Internal sehingga hasil hipotesis pertama terbukti kebenarannya.

\section{Tabel 4}

Hasil Uji Partial X-Y2 Coefficients $^{\mathrm{a}}$

\begin{tabular}{|l|r|r|r|r|r|}
\hline Model & \multicolumn{2}{|c|}{$\begin{array}{c}\text { Unstandardized } \\
\text { Coefficients }\end{array}$} & $\begin{array}{c}\text { Standardized } \\
\text { Coefficients }\end{array}$ & \multirow{2}{*}{ Sig. } \\
\cline { 2 - 5 } & \multicolumn{1}{|c|}{$\mathrm{B}$} & $\begin{array}{c}\text { Std. } \\
\text { Error }\end{array}$ & Beta & & \\
\hline (Constant) & 9,807 & 5,987 & & 1,638 &, 107 \\
1 Peran &, 780 &, 117 &, 657 & 6,644 &, 000 \\
Auditor & & & & & \\
Internal & & & & & \\
\hline
\end{tabular}

a. Dependent Variable: Pencegahan Fraud

Sumber: Hasil dari SPSS 21 (Diolah sendiri, 2020)
Berdasarkan tabel 4 dapat dilihat bahwa nilai $\mathrm{t}$ hitung pada Pencegahan Fraud adalah sebesar 6.644, t tabel sebesar 2.001 dengan tingkat signifikansi sebesar 0,000 . Karena nilai $t_{\text {hitung }}>t$ tabel yaitu $6.644>2.001$ dan nilai signifikansi $0.000<0.5$ maka Ho ditolak dan Ha diterima. Hal ini berarti Pencegahan Fraud berpengaruh signifikan terhadap Peran Auditor Internal sehingga hasil hipotesis kedua terbukti kebenarannya.

\subsection{Pembahasan}

\section{Peran Auditor Internal dalam Pendeteksian Fraud}

Hasil penelitian variabel Peran Auditor Internal terhadap Pendeteksian Fraud pada Bank Syariah di Kota Bandung menyatakan bahwa variabel Peran Auditor Internal berpengaruh secara signifikan terhadap Pendeteksian Fraud. Hal ini terbukti dengan hasil penelitian yang menunjukan pengaruh sebesar 26,72\% dengan probabilitas signifikansi 0.000 . karena nilai $\mathrm{t}$ hitung $>\mathrm{t}$ tabel yaitu $4.596>2.001$ dan nilai signifikansi $0.000<0.5$ maka Ho ditolak dan $\mathrm{Ha}$ diterima.

Hal ini berarti bahwa Peran Auditor Internal berpengaruh secara signifikan terhadap Pendeteksian Fraud pada Bank Syariah di Kota Bandung. Hipotesis pertama yang menyatakan ada pengaruh yang signifikan antara Peran Auditor Internal terhadap Pendeteksian Fraud dapat dibuktikan kebenarannya. Hasil penelitian ini konsisten dengan hasil penelitian (Amelia, 2014) yang menyatakan bahwa Auditor Internal berpengaruh secara signifikan terhadap Pendeteksian Fraud.

(Amelia, 2014) mendeteksi kecurangan adalah upaya untuk mendapatkan indikasi awal yang cukup mengenai tindakan fraud, sekaligus mempersempit ruang gerak para pelaku kecurangan. Kecurangan dapat dibongkar oleh Auditor Internal karena adanya indikasi awal serta perencanaan yang baik untuk menyingkap sesuatu mengenai tindak kecurangan / Fraud. Salah satu indikator dari Peran Auditor Internal yang dapat mendorong auditor untuk lebih baik dalam mendeteksi kecuarangan adalah mandiri yang salah satunya yaitu independensi. Apabila Auditor Internal memiliki sikap independensi yang baik maka Auditor Internal akan dengan mudah dalam melakukan Pendetekian Fraud. Tetapi pada kenyataan sebenarnya di lapangan bahwa terdapat beberapa indikator dari Peran Auditor Internal yang masih dibawah rata-rata yaitu tentang mandiri. Bahwa dalam indikator tersebut salah satunya adalah auditor internal tidak dapat di intervensi terhadap pekerjaannya. 


\section{Jurnal Ilmiah Ekonomi Islam, 6(03), 2020, 533}

Kenyataan sebenarnya di Bank Syariah di Kota Bandung auditor internalnya sendiri masih dapat di intervensi dalam melakukan pekerjaannya atau dalam kata lain auditor internalnya sendiri belum bisa menerapkan salah satu kode etik dari seorang auditor yaitu independensi, ini dibuktikan dilihat dari tanggapan responden yang tertera pada kuisioner.

Pada dasarnya tindak fraud dapat dibongkar oleh auditor internal karena adanya indikasi awal secara perencanaan yang baik untuk menyingkap segala sesuatu mengenai tindak fraud yang mungkin terjadi. Dalam mendeteksi fraud juga diperlukan proses pengujian oleh Auditor Internal terhadap obyeknya. Proses pengujian ini menjadi salah satu pendorong dalam melakukan Pendeteksian Fraud, karena dalam proses ini Auditor Internal bisa memperoleh indikasi kuat bahwa diperlukan atau tidaknya tindakan yang lebih mendalam ataupun diperlukan suatu investigasi tertentu. Pada kenyataannya di Bank Syariah di Kota Bandung Auditor Internalnya masih belum baik dalam melakukan pengujian terhadap obyek dibuktikan dengan hasil tanggapan responden yang tertera pada kuisioner memiliki nilai dibawah rata-rata. Mendeteksi fraud juga merupakan upaya untuk mendapatkan indikasi awal yang cukup mengenai tindak fraud, sekaligus mempersempit ruang gerak para pelaku fraud (yaitu ketika pelaku menyadari prakteknya telah diketahui, maka sudah terlambat untuk berkelit. Auditor Internal yang dibutuhkan dalam mendeteksi fraud disini haruslah Auditor Internal yang memiliki intuisi yang tajam melihat berbagai aspek internal perusahaan yang riskan (rawan) terjadi fraud. Sehingga dapat disimpulkan bahwa Peran Auditor Internal mempunyai pengaruh secara signifikan terhadap Pendeteksian Fraud pada Bank Syariah di Kota Bandung.

\section{Peran Auditor Internal terhadap Pencegahan Fraud}

Hasil penelitian variabel Peran Auditor Internal terhadap Pencegahan Fraud pada Bank Syariah di Kota Bandung menyatakan bahwa variabel Peran Auditor Internal berpengaruh signifikan terhadap Pencegahan Fraud. Hal ini terbukti dengan hasil penelitian yang menunjukan pengaruh sebesar $43,16 \%$ dengan probabilitas signifikansi 0.000 . karena nilai $t$ hitung $>\mathrm{t}$ tabel yaitu $6.644>2.001$ dan nilai signifikansi $0.000<0.5$ maka Ho ditolak dan Ha diterima.

Hal ini berarti bahwa Peran Auditor Internal berpengaruh secara signifikan terhadap Pencegahan Fraud. Hipotesis pertama yang menyatakan ada pengaruh yang signifikan antara Peran Auditor Internal terhadap Pencegahan Fraud dapat dibuktikan kebenarannya.

Hasil penelitian ini konsisten dengan hasil penelitian (Kumaat, 2012) dalam penelitiannya memperoleh nilai signifikansi sebesar $0.000<0.05$, artinya Peran Auditor Internal berpengaruh signifikan terhadap Pencegahan Kecurangan. Auditor Internal adalah sebagai pengawas terhadap tindak kecurangan. Auditor Internal bertanggung jawab untuk membantu manajemen mencegah kecurangan dengan melakukan pengujian dan evaluasi keandalan dan efektifitas dari pengendalian intern seiring dengan potensi resiko terjadinya kecurangan dalam berbagai segmen.

(Kumaat, 2012) menyebutkan bahwa indikatorindikator dari pendeteksian fraud adalah (1) Pemetaan untuk mengidentifikasi titik-titik kritis risiko terjadinya tindak fraud; (2) Pengamatan untuk memperdalam semua titik risiko berdasarkan situasi aktual di lapangan; (3) Verifikasi transaksi dan analisis data untuk mempertegas kesimpulan bahwa tindakan fraud mungkin ada atau rawan terjadi; (4) Memiliki staf berpengalaman, khususnya staf yang peka terhadap sinyal fraud dan (5) Pengujian dan Pengevaluasian.

Salah satu indikator dari Pencegahan Fraud yaitu dengan menetapkan aturan untuk mencegah fraud. Auditor Internal dengan menetapkan aturan tersebut maka akan dapat meminimalisir sebab-sebab timbulnya kecurangan. Menetapkan aturan untuk mencegah fraud dapat memperkecil terjadinya peluang kesempatan untuk berbuat curang, serta mengeliminasi alasan untuk membuat pembenaran atas rasionalisasi tindakan fraud yang dilakukan. Pada kenyataannya di Bank Syariah di Kota Bandung Auditor internal belum baik dalam menetapkan aturan untuk mencegah terjadinya kecurangan. Dapat dibuktikan berdasarkan tanggapan responden yang tertera pada kuisioner memiliki nilai dibawah ratarata.

Kasus fraud yang semakin marak terjadi membuat kerugian yang cukup besar bagi perusahaan. Apabila fraud tidak bisa dideteksi dan dihentikan, maka akan berakibat fatal bagi perusahaan. Untuk itu, dibutuhkan peran Auditor Internal yang harus bisa mengambil tindakan yang tepat untuk mencegah terjadinya fraud. Dengan adanya upaya pencegahan yang tepat yang telah diterapkan oleh Auditor Internal, perusahaan dapat memperkecil peluang terjadinya fraud karena setiap tindakan fraud dapat tercegah 
dengan cepat dan diantisipasi dengan baik oleh Auditor Internal Perusahaan. Setiap karyawan tidak merasa tertekan lagi dan tidak melakukan pembenaran terhadap tindakan fraud yang dapat merugikan banyak pihak, apabila teknik pencegahan fraud berjalan baik dan efektif akan membuat citra positif bagi Perusahaan karena meningkatkan kepercayaan publik. Sehingga dapat disimpulkan bahwa Peran Auditor Internal mempunyai pengaruh secara signifikan terhadap Pencegahan Fraud pada Bank Syariah di Kota Bandung.

\section{KESIMPULAN}

Peran Auditor Internal memiliki pengaruh terhadap Pendeteksian Fraud. Ini menunjukan bahwa semakin tinggi atau baik peran auditor internal dalam menjalankan auditnya sesuai prosedur audit maka semakin tinggi atau baik pula upaya untuk mendeteksi atau mendapatkan indikasi awal mengenai tindak fraud. Begitupun sebaliknya apabila Peran Auditor Internal masih rendah atau belum baik dalam melaksanakan tugasnya kecurangan tidak dapat terdeteksi dengan baik. Peran Auditor Internal memiliki pengaruh terhadap Pencegahan Fraud. Ini dapat disimpulkan bahwa semakin baik Peran Auditor Internal menjalankan internal control akan membuat Pencegahan Fraud semakin efektif. Pencegahan kecurangan dapat dilakukan apabila Auditor Internal bersikap mandiri dan profesional dalam pekerjaannya, kemudian Auditor Internal sudah mampu mengidentifikasi. Sebaliknya, ketika Auditor Internal bekerja tidak profesional dan tidak mampu mengidentifikasi maka kecurangan akan terjadi dan membuat kerugian bagi perusahaan.

Penelitian ini tidak terlepas dari kekurangan dan keterbatasan-keterbatasan dalam penelitian ini diantaranya dalam teknik pengambilan sampel hanya sebanyak 60 responden dengan random sampling. Sehingga penelitian selanjutnya sebaiknya menambah jumlah sampel agar penelitian selanjutnya lebih akurat dan pengkajian pernyataan dalam kuesioner lebih ditingkatkan.

\section{UCAPAN TERIMA KASIH}

Peneliti mengucapkan terimakasih kepada semua responden yang dengan ikhlas membantu dalam menyelesaikan penelitian ini. Terimakasih untuk pihak pengelola Jurnal JIEI STIE Surakarta atas kesempatannya. Terimakasih pula untuk Fakultas Ekonomika dan Bisnis Universitas Majalengka yang telah memberikan fasilitas untuk peneliti dalam menyelesaikan penelitian ini.

\section{REFERENSI}

Amelia, R. (2014). Pengaruh Audit Internal terhadap Pencegahan dan Pendeteksian Fraud (Studi Kasus Pada Koperasi Sewilayah Bandung).

Arief, T. (2019). Kasus Kredit Fiktif Bank BJB Syariah, Bareskrim Buru Tersangka Lain.

Badan Pengawas Keuangan dan Pembangunan. (2015). Fraud Auditing Edisi 10. In Pusdiklatwas BPKP.

Badan Pengawas Keuangan dan Pembangunan. (2020). No Title.

Kamus Besar Bahasa Indonesia. (2015). No Title. Jakarta: Balai Pustaka.

Kumaat, V. (2012). Internal Audit. Jakarta: Erlangga. Nasim, A., \& Mediawati, E. (2019). Critical Study the Application of the Principle of Profit Sharing in Syirkah Mudharabah and Musyarakah in Islamic Banking. KnE Social Sciences, 1351-1359.

Otoritas Jasa Keuangan. (2020). No Title.

Santosa, S., Tho'in, M., \& Sumadi. (2020). Analisis

Tingkat Kesehatan Bank Syariah Menggunakan Rasio Permodalan, Profitabilitas, Pembiayaan, dan Risiko Kredit. 6(02), 367-371.

Sugiyono. (2018). Metode Penelitian. Bandung: CV Alfabeta.

Tuanakotta, T. (2012). Audit Berbasis ISA Edisi II. Jakarta: Salemba Empat.

Tugiman, H. (2013). Standar Profesional Audit Internal. Jakarta: Kanisius.

Widaningsih, M., \& Hakim, D. N. (2015). Pengaruh Profesionalisme Auditor Internal Terhadap Pencegahan dan Pendeteksian Kecurangan (Fraud) (Survey pada BUMN yang Berkantor Pusat di Kota Bandung). Jurnal Riset Akuntansii Dan Keuangan, 3(1), 586-602. 